\title{
Demand forecasting, Economic Order Quantity and inventory costs calculation of a company producing solar panels
}

\author{
Puneet Bhatia*, Kartik Gupta** \& Rishabh Dua*** \\ *Department of Mechanical, Production and Automobile Engineering, Delhi Technological University, Delhi, \\ India \\ **Department of Mechanical, Production and Automobile Engineering, Delhi Technological University, Delhi, \\ India \\ ***Department of Mechanical, Production and Automobile Engineering ,Delhi Technological University, \\ Delhi, India
}

\begin{abstract}
Forecasting accuracy drives the performance of inventory management. This study involves forecasting the sales of PV modules of a solar panel manufacturing company by demand forecasting methods including regression and exponential smoothing models. Demand forecasted is used to control inventory, minimize cost of ordering and holding inventory. The model should propose a viable economic order quantity which reduces the total cost of the plan.
\end{abstract}

\section{Introduction}

ORRECT forecasting has become a need for survival in today's business world. Not only for production unit but correct forecasting is required at every stage of product development. It is a foundation upon which the all company plan and objectives are built in terms of market and revenue. Correct forecasting helps save wastage in materials, man hours, machine idle time etc which leads to increased efficiency and productivity. Exponential smoothening and regression models have been potently used as they are the most cost effective statistical tools.

With the advent of rapid industrialization, increased locomotives and energy needs, there is a need to shift to renewable forms of energy to fulfill our energy needs. Thus, the dataset selected is that of Solar Panel which under general consensus states the rising demand of solar panels signifies the rising acceptance of using solar energy as a viable alternative energy source. Solar Panel refers to a panel designed to absorb the sun's rays which is an ultimate source of energy for generating electricity or heat. The factor that has hampered the production of solar panels is the high installation and starting cost but as the acceptance of solar panels rises the cost of setting up solar panels has been seen to be decreasing. From the past demand curves, as stated by Swanson's law which states that with every doubling of production of panels, there has been a 20 percent reduction in the cost of panels, which holds true within the limit of error.

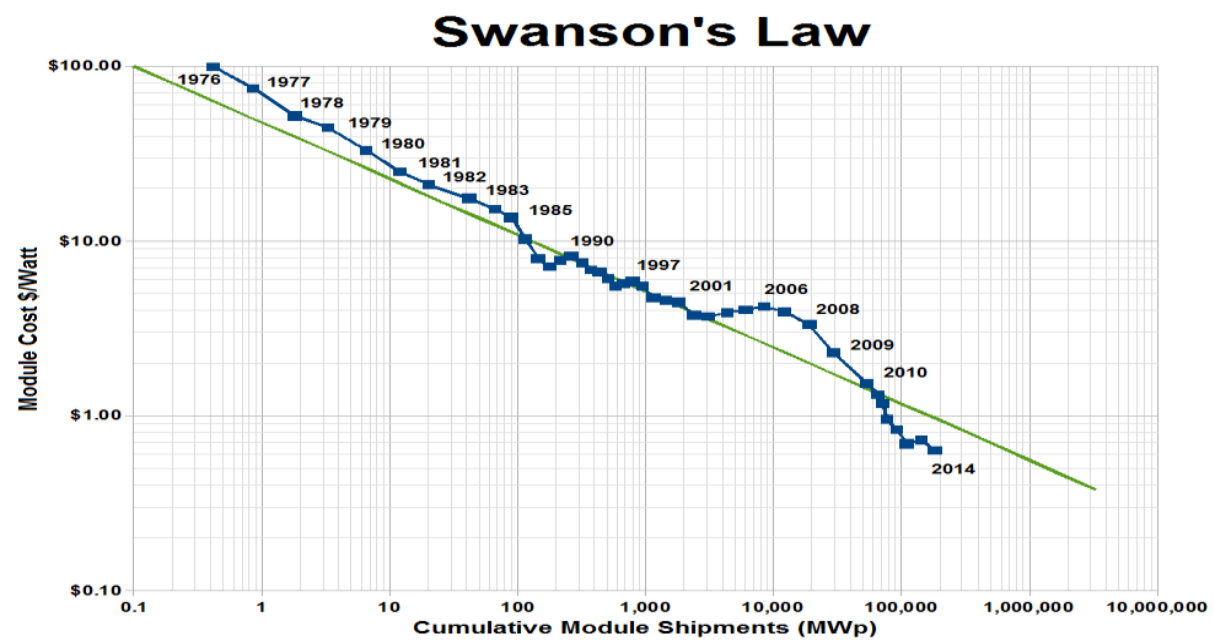

The demand forecasts form a key input to the economic appraisal. As such any errors present within the demand forecasts will undermine the reliability of the economic appraisal. Moreover, incorrect forecasts could create several problems such as over or under production, wastage etc, in the organization as forecasting forms a key input to the planning function. The study aims to efficiently forecast demand for solar panels for a 
Demand forecasting, Economic Order Quantity and inventory costs calculation of a company..

solar panel manufacturing company and develop an adequate inventory control model along with determining the optimum order quantity for regulating the storage of silicon, which is a key raw material in manufacturing of solar panels.

\section{Methodology}

Two methods used in this study were Exponential Smoothing and Non Linear (Polynomial) Regression: Exponential Smoothing: It calculates the smoothed series as a damping coefficient times the actual series plus 1 minus the damping coefficient times the lagged value of the smoothed series. The extrapolated smoothed series is a constant, equal to the last value of the smoothed series during the period when actual data on the underlying series are available. While the simple Moving Average method is a special case of the ES, the ES is more parsimonious in its data usage.

Where:

$$
F_{t}+1=\alpha D_{t}+(1-\alpha) F_{t}
$$

- $\quad \mathrm{D}_{\mathrm{t}}$ is the actual value

- $\mathrm{F}_{\mathrm{t}}$ is the forecasted value

- $\alpha$ is the weighting factor, ranging from $0-1$

- $\quad t$ is the current time period.

Notice that the smoothed value becomes the forecast for period $t+1$.

Non Linear Regression:

In statistics, nonlinear regression is a form of regression analysis in which observational data are modeled by a function which is a nonlinear combination of the model parameters and depends on one or more independent variables. The data are fitted by a method of successive approximations. We have used the polynomial regression by fitting and extrapolating our data in an equation of the form of $\mathrm{y}=\mathrm{Ax}{ }^{2}+\mathrm{Bx}+\mathrm{C}$

Where $\mathrm{y}$ is the dependant variable and $\mathrm{x}$ is the independent variable.

\section{Research Elaborations}

The material balance suggests that 5 grams of polysilicon is required per watt of c-Si PV Module.

The wattage of PV Module is 250 . Hence raw material (polysilicon) required per module $=250 * 5=1250 \mathrm{~g}=$ $1.25 \mathrm{~kg}$

\section{Forecasting of demand by Exponential Smoothing:}

Demand forecasted by Exponential Smoothing is given in Table 1.

Total demand of PV Modules for the financial year $2015=11463985$ units

Raw material (polysilicon) required $=1.25 * 11463985=14329981.25 \mathrm{~kg}=14329.981$ tons

Holding Cost/ton/Year $(\mathrm{C})=1840$

Fixed Cost per Order $(\mathrm{F})=1230645$

EOQ of polysilicon $=4378$ tons

No of reorders per year $=3.27$

Inventory costs of polysilicon

Ordering costs $=$ Rs 4028127

Holding costs $=$ Rs4027760

\section{Total inventory costs $=$ Rs 8055880}

Forecasting of demand by regression:

Demand forecasted by Polynomial Regression is given in Table 2.

Total demand of PV Modules for the financial year $2015=14846575$ units

Raw material (polysilicon) required $=1.25 * 14846575.13=18558219 \mathrm{~kg}=18558.219$ tons

Holding Cost/ton/Year $(\mathrm{C})=$ Rs 1840

Fixed Cost per Order $(\mathrm{F})=$ Rs 1230645

EOQ of polysilicon $=4982$ tons

No of reorders per year $=3.725$

Inventory costs of polysilicon

Ordering costs $=$ Rs 4584140

Holding costs $=$ Rs 4583440

Total inventory costs $=9166880$

\section{Results}

In this work demand of PV modules is forecasted by Exponential smoothing and regression methods. EOQ and no of orders of polysilicon is calculated with the help of forecasted demand. Inventory costs, raw 
Demand forecasting, Economic Order Quantity and inventory costs calculation of a company..

material holding costs and ordering costs of polysilicon for the financial year 2015 is obtained. Total inventory costs of the demand forecasted by exponential smoothing is $13.8 \%$ less than the total inventory costs of the demand forecasted by regression.

\section{Conclusion}

The world is moving towards renewable resources and solar energy is a very important dimension in it. In order to help the company, producing solar panels, reduce their stock outs, a forecasting model was provided along with an economic order quantity. Finally, the economic order quantity is, optimized the order quantity for each product when an order is placed, reducing the company's product stock out issue. By providing and recommending the inventory control model, the results have shown improvements in forecasting as well as in cost reduction. The error associated with the model by exponential smoothing is $18 \%$, and the error associated with the regression model is $11 \%$. Thus the regression model is a more accurate representation of the increasing trend in the solar panel demand. The total inventory cost is however more in the regression model, this also leads to a safety in spikes and randomness which may arise due to unregulated demand for the future. Thus the regression model benefits in both the aspects. The recommended analysis showed that simple, yet complex techniques are the key for retail success which could give them the competitive edge.

Table 1: Actual Demand

\begin{tabular}{|l|l|l|}
\hline Quarter & DEMAND $(\mathbf{M W})$ & DEMAND - UNITS OF MODULES \\
\hline 3Q12 & 245.5242967 & 982097 \\
\hline 4Q12 & 251.6624041 & 1006650 \\
\hline 1Q13 & 251.6624041 & 1006650 \\
\hline 2Q13 & 257.8005115 & 1031202 \\
\hline 3Q13 & 306.9053708 & 1227621 \\
\hline 4Q13 & 365.2173913 & 1460870 \\
\hline 1Q14 & 389.769821 & 1559079 \\
\hline $2 Q 14$ & 448.0818414 & 1792327 \\
\hline 3Q14 & 693.6061381 & 2774425 \\
\hline 4Q14 & 880.8184143 & 3523274 \\
\hline 1Q15 & 586.1892583 & 2344757 \\
\hline 2Q15 & 721.2276215 & 2884910 \\
\hline 3Q15 & 1077.237852 & 4308951 \\
\hline
\end{tabular}

Table 3: Forecast using Polynomial Regression

\begin{tabular}{|l|l|l|l|}
\hline Quarter & Forecast & Absolute Error & \% Absolute Error \\
\hline 3Q12 & 917608 & 64490 & 0.065665096 \\
\hline 4Q12 & 953900 & 52749 & 0.052400888 \\
\hline 1Q13 & 1029155 & 22505 & 0.022356429 \\
\hline 2Q13 & 1143371 & 112169 & 0.108774909 \\
\hline 3Q13 & 1296549 & 68928 & 0.056147226 \\
\hline 4Q13 & 1488689 & 27819 & 0.019043009 \\
\hline 1Q14 & 1719791 & 160711 & 0.103080933 \\
\hline 2Q14 & 1989854 & 197527 & 0.110206878 \\
\hline 3Q14 & 2298880 & 475545 & 0.171403119 \\
\hline 4Q14 & 2646867 & 876407 & 0.248747906 \\
\hline 1Q15 & 3033816 & 689059 & 0.293872105 \\
\hline 2Q15 & 3459727 & 574816 & 0.199249184 \\
\hline 3Q15 & 3924599 & 384352 & 0.089198548 \\
\hline 4Q15 & 4428434 & & $\mathbf{1 1 . 8 4 7 2 7 8 7}$ \\
\hline
\end{tabular}

Table 2: Forecast Using Exponential Smoothing

\begin{tabular}{|l|l|l|l|}
\hline Quarter & Forecast $(\boldsymbol{\alpha}=\mathbf{0 . 7})$ & Absolute Error & \% Absolute Error \\
\hline 3Q12 & & & \\
\hline 4Q12 & 982097 & 24552 & 0.024390244 \\
\hline 1Q13 & 999284 & 7366 & 0.007317073 \\
\hline 2Q13 & 1004440 & 26762 & 0.025952381 \\
\hline 3Q13 & 1023173 & 204448 & 0.16654 \\
\hline 4Q13 & 1166287 & 294583 & 0.201648739 \\
\hline 1Q14 & 1372495 & 186584 & 0.119676063 \\
\hline 2Q14 & 1503104 & 289223 & 0.161367521 \\
\hline 3Q14 & 1705560 & 1068864 & 0.385256183 \\
\hline 4Q14 & 2453765 & 1069508 & 0.303555293 \\
\hline 1Q15 & 3202421 & 857664 & 0.365779525 \\
\hline 2Q15 & 2602056 & 282854 & 0.098046099 \\
\hline 3Q15 & 2800054 & 1508897 & 0.35017735 \\
\hline 4Q15 & 2859454 & & $\mathbf{1 8 . 4 1 4 2 2 0 6}$ \\
\hline
\end{tabular}

Table 4: Values of coefficients in the equation $\mathrm{Ax}^{2}+\mathrm{Bx}+\mathrm{C}$ : Polynomial Regression 


\begin{tabular}{|l|l|}
\hline $\mathrm{A}$ & 19480.91 \\
\hline $\mathrm{B}$ & -22150.1 \\
\hline $\mathrm{C}$ & 920276.9 \\
\hline
\end{tabular}

Graph 1: Actual v Forecast: Exponential Smoothing

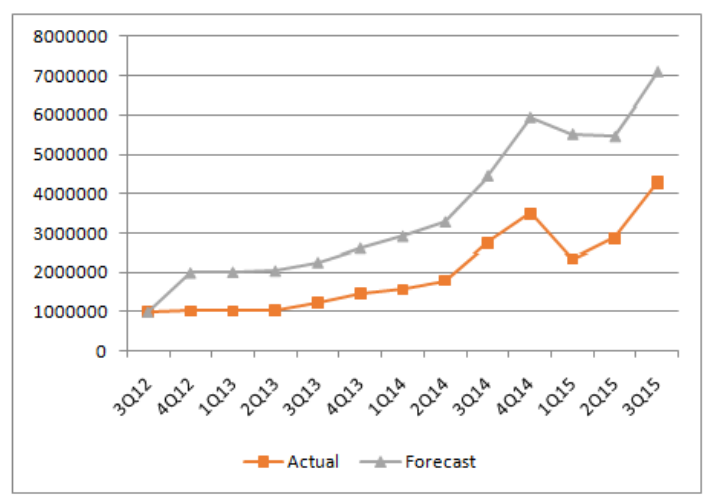

Graph 2: Actual v Forecast: Polynomial Regression

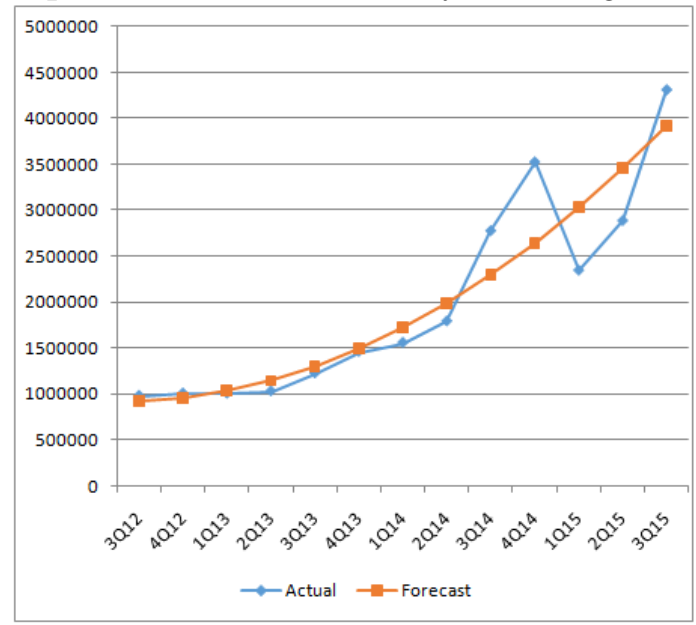

\section{References}

[1]. Aju Mathew, Prof.E.M.Somasekaran Nair, Asst Prof. Jenson Joseph E, Demand Forecasting For Economic Order Quantity in Inventory Management, International Journal of Scientific and Research Publications, Volume 3, Issue 10, October 20131 ISSN 2250-3153

[2]. Bhupesh Verma, Ganeshprasad P. and Dr. Sharath Rao CSTEP, Bangalore, Polysilicon Manufacturing in India: Go or No-Go

[3]. JA solar annual report 2015

[4]. http://www.madehow.com/Volume-1/Solar-Cell

[5]. Industrial engineering and management by Pravin Kumar 